\title{
APPLICATION OF MOLECULAR TECHNIQUES IN WINE MICROBIOLOGY*
}

\author{
A review \\ T. DEÁK** \\ Department of Microbiology and Biotechnology, Faculty of Food Science, Szt. István University, \\ H-1118 Budapest, Somlói út 14-16. Hungary \\ (Received 13 December 2000; accepted: 6 August 2001)

\begin{abstract}
Wine fermentation is a complex microbiological process in which yeasts predominate. It is long debated whether yeasts occurring on the surface of grapes or the resident yeasts on the winery equipment play the primary role in conducting the fermentation. The origin, development, changes and succession of various yeast species can be followed using specific molecular techniques allowing the differentiation and typing of yeast strains. Techniques such as pulsed field gel electrophoresis of chromosomal DNA, restriction fragment length polymorphism analysis, and polymerase chain reaction (PCR)-based methods have recently been employed in studying the microbiology of wine making. These shed new light on the dynamics of fermentation started spontaneously or directed by the inoculation of starter cultures.
\end{abstract}

Keywords: wine yeast, Saccharomyces, PFGE, RFLP, RAPD, PCR

Fermentation of must into wine is a complex microbiological process in which yeast play a primary role but lactic acid bacteria and moulds also take part. The spontaneous alcoholic fermentation is carried out by the resident yeasts on grape berries and winery equipment. Different yeast species follow each other in succession according to their degree of ethanol tolerance. Although fermentation is usually started by the apiculate yeasts (Hanseniaspora and Kloeckera species), after a few days they die out together with the so-called wild yeasts (Metschnikowia, Pichia, Candida species), and the genuine wine yeasts become predominant. Several species of wine yeasts were recognised earlier, such as Saccharomyces cerevisiae, S. ellipsoideus, S. oviformis, $S$. chevalieri and others. According to the current classification they all belong to the group called Saccharomyces sensu stricto, mostly to $S$. cerevisiae, and some cold tolerant strains to S. bayanus.

\footnotetext{
* Based on the lecture presented at the Károly Vas Memorial Meeting at the St. István University, Budapest, on 6 September, 2000.

**E-mail: tdeak@omega.kee.hu
} 
The origin of wine yeasts - an old debate

It is still debated whether the wine yeasts originate from the grapes or their main sources are the winery equipments (harvesting containers, presses, barrels) from where they get into the fresh must. The idea first proposed by Pasteur and supported also by Hansen, Guilliermond and other great zymologists of the 19th century, has been that yeasts survive wintertime on berries fallen on the soil from where they are transferred again to new grape berries by drosophilas at the next growing season. Main proponents of the opposing view are Professor Martini and his co-workers at the University of Perugia, Italy, who demonstrated that wine yeasts occur very rarely on grapes even at the time of ripening. In turn, they are abundant on the surfaces of winery equipments which can be considered as the primary source of wine yeasts. Moreover, winery plant and cellars are inhabited by specific strains of Saccharomyces wine yeasts adapted to the particular environment and wine growing region (MARTINI, 1993). Contrary to this scenario, at a recent International Symposium on Yeasts held in 1996 in Sydney, Dr. Bob Mortimer and his co-workers presented new evidence for the grape origin of wine yeasts (TÖRÖK et al., 1996).

\section{Specific wine yeasts}

Whatever the case may be, a diverse population of yeasts is associated with grapes, and their number and types are influenced by numerous factors such as climate, weather conditions, grapevine cultivar, degree of ripening, agrotechnique and others. Consequently, remarkable differences can be observed in the organoleptic quality of wine produced in subsequent years. It is also known that wine yeast strains isolated from various wine regions show considerable differences in their physiological properties. Many of them are of technological significance, such as tolerance to ethanol, high sugar content, sulphur dioxide and cold resistance. In several wine producing countries wine yeasts with these specific properties have been collected and maintained. (In Hungary, collection of wine yeasts began in the 1930s by István Soós, and continued by Géza Requinyi and others. A large collection of wine yeasts is preserved and maintained at the National Collection of Agroindustrial Microorganisms [NCAIM] in Budapest). Specific wine yeasts can be used as starter inocula to hasten and control fermentation and to produce wine of uniform quality in large quantities. In this respect, some wine makers question if the properties of wine yeasts would have a large impact on quality, or whether the characteristics of the wine are determined primarily by the grape cultivar and cellar manufacturing.

Contrary to doubts, intensive research work has been done to breed wine yeast strains with improved features. With the advent of molecular biology and its application in biotechnology, new possibilities have arisen to construct genetically engineered yeast strains. Successful results were attained at laboratory scale, e.g. to introduce the gene of malolactic enzyme into $S$. cerevisiae for producing softer red wine. The protoplast fusion technique, first developed by Professor Ferenczy in Szeged, appeared very promising to construct hybrid strains (MARÁz \& DEÁK, 1990, SADDEKNI et al., 1988). 
At this time, however, international regulations hinder the practical application, especially for food production, of genetically modified organisms (GMOs), including yeasts.

\section{New tools of quest: molecular techniques}

Novel techniques developed by molecular biology provide excellent tools to look into, and clarify old problems in wine microbiology, not tractable by conventional test methods. Nucleic acid-based methods, such as deoxyribonucleic acid (DNA) hybridisation, restriction enzyme analysis, electrophoresis of chromosomal DNA, sequencing of DNA, and methods using the polymerase chain reaction (PCR) have found application in wine microbiology (DEÁK, 1995; QUEROL \& RAMÓN, 1996; MOŽINA \& RASPOR, 1997). Examples will be presented in the following.

Several DNA-based methods provide a specific fingerprint of the yeast genom (total genetic material) and not only permit the identification of individual species, but also the discrimination of strains belonging to the same species (called typing). One of these techniques, the pulsed field gel electrophoresis (PFGE) for the separation of large DNA molecules has been first developed to study the chromosomal constitution (karyotype) of yeasts. Basically, the DNA extracted from the cell by gentle treatment to avoid breaking of long molecules is subjected to continuously reorienting electric fields. Long molecules need more time to follow reorientation than smaller ones, and this results in differences in their migration on the gel and eventually separation according to size (Fig. 1). The bands of molecules are made visible under UV light after staining. The banding pattern (the number and size of chromosomal DNA, i.e. the karyotype) is characteristic of species, and smaller differences (polymorphism) can also be found between strains. Judit Lehoczki and her co-workers at the NCAIM have investigated the karyotypes of wine yeasts maintained in the collection (TORNAI-LEHOCZKI \& DLAUCHY, 1996), and found that strains belonging to the species S. cerevisiae can be distinguished from closely related species, $S$. bayanus, and also from the brewing yeast, $S$. pastorianus (Fig. 2). Individual strains could also be differentiated.

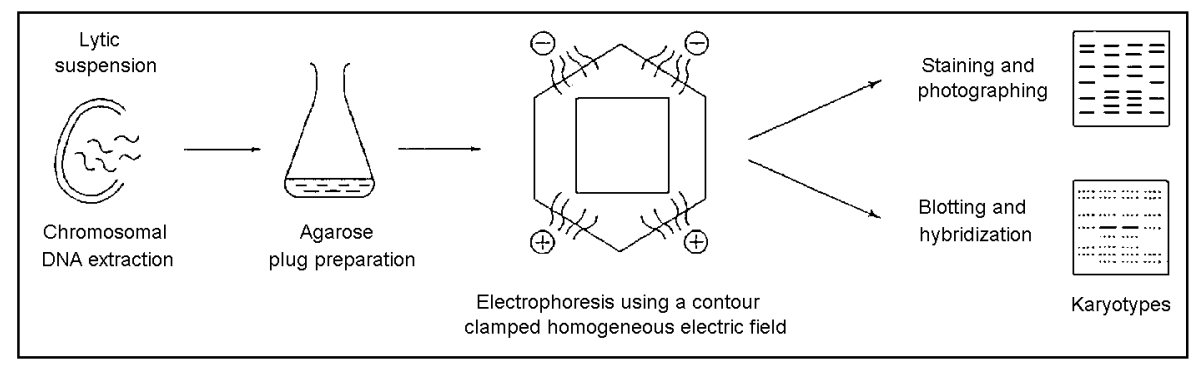

Fig. 1. Schematic diagram of chromosome karyotyping by pulsed field gel electrophoresis 


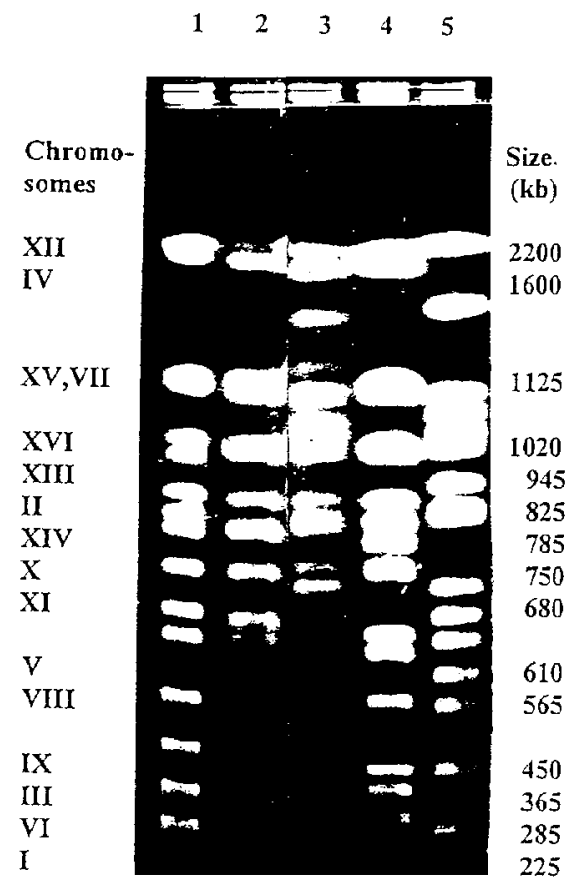

Fig. 2. Karyotypes of Saccharomyces sensu stricto species. Separation of chromosomal DNAs by rotating field electrophoresis. Lanes: 1: S. cerevisiae YNN 295 (Biorad standard); 2: S. cerevisiae neotype strains DBVPG 6173; 3: S. pastorianus type DBVPG 6047; 4: S. paradoxus neotype DBVPG 6411; 5: S. bayanus type DBVPG 6171. Courtesy of J. Tornai-Lehoczki

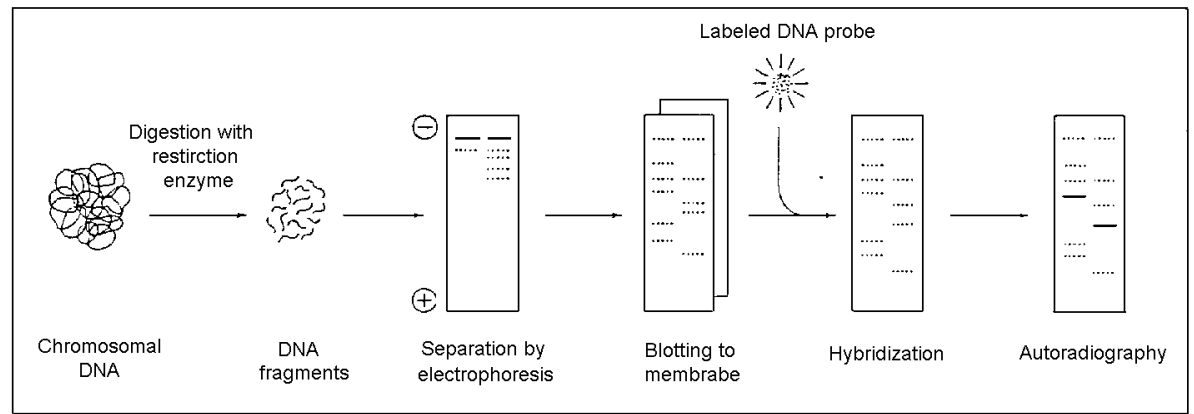

Fig. 3. Schematic diagram of restriction fragment length polymorhism (RFLP) analysis

Other molecular techniques produce fingerprints of DNA fragments. In restriction fragment length polymorphism (RFLP) analysis the total cell DNA is digested by 
restriction endonuclease enzymes which cleave the molecule at specific short sequences of nucleic acid bases. The resulting fragments are separated by gel electrophoresis, and can be visualised directly on the gel, or after transferring to synthetic membrane support and hybridised with labelled DNA probes (Fig. 3). These DNA probes are short oligonucleotides which represent specific regions of the genome (e.g. parts of genes) and anneal to the sample DNA only if complementary sequences are found. The RFLP method is very specific, however, laborious and requires long time to complete. In the case of yeasts it is easier to apply this technique only to the mitochondrial DNA (mtDNA) instead of the whole genome. The simpler banding pattern can be evaluated without DNA probes. A research group lead by Amparo Querol at the University of Valencia has developed a rapid method for the RFLP analysis of mtDNA, and using it for the typing of yeast they obtained evidence that wine yeast strains differ according to wine regions, grape cultivars and even wine cellars (QUEROL et al., 1994; GUILLAMÓN et al., 1996). Using both PFGE and RFLP techniques a French research group demonstrated that characteristic yeast strains predominated in different cellars in two wine regions during six successive years (VEZINHET et al., 1992).

\section{The destination of yeast starters}

The results cited above may provide convincing evidence to support the significant role played by specific wine yeast in developing the character of wine. DNA fingerprinting make also possible to follow the traces of starter wine yeast strain after inoculation and during the fermentation. In addition to the methods mentioned so far, another one has been also very efficient to look into this question. The method is based on an ingenious technique, the polymerase chain reaction (PCR) to perform DNA replication in vitro.

In the PCR, the DNA molecule is first denatured by heat into single strands and to these a pair of specific short DNA fragments (primers) are annealed at lower temperature. DNA polymerase extends the complimentary sequences at its optimum temperature of activity (Fig. 4). After repeating this thermo-cycle for 30-40-times, the sequence between the primers becomes amplified millionfold.

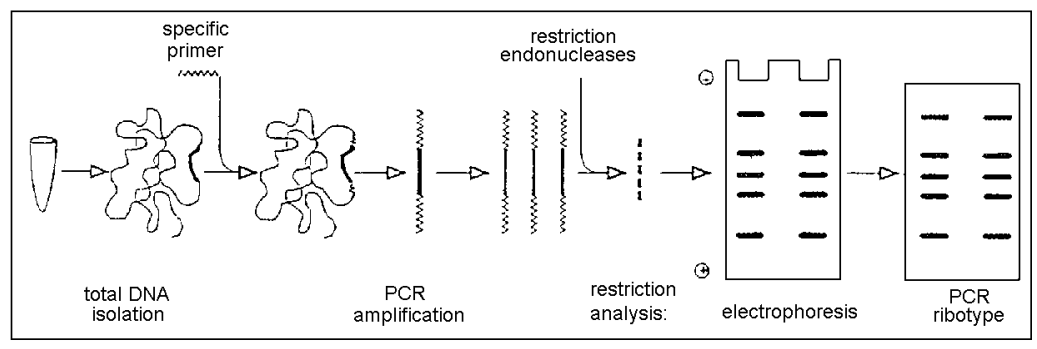

Fig. 4. Schematic diagram of polymerase chain reaction (PCR) 
The specificity of the reaction is determined primarily by the oligonucleotide primer. In PCR-ribotyping, definition of primers are based on highly conserved sequences of the rRNA genes. The spacers between these genes, termed internal transcribed spacer (ITS) appeared variable enough to allow the identification of species (MoŽINA et al., 1997). Fig. 5 shows electrophoretic ribotypes of various Saccharomyces species and related yeasts, prepared by Dénes Dlauchy at the NCAIM. Specific discrimination is enhanced by the use of a restriction enzyme to produce fragments of different size of the amplified products (DLAUCHY et al., 1999).

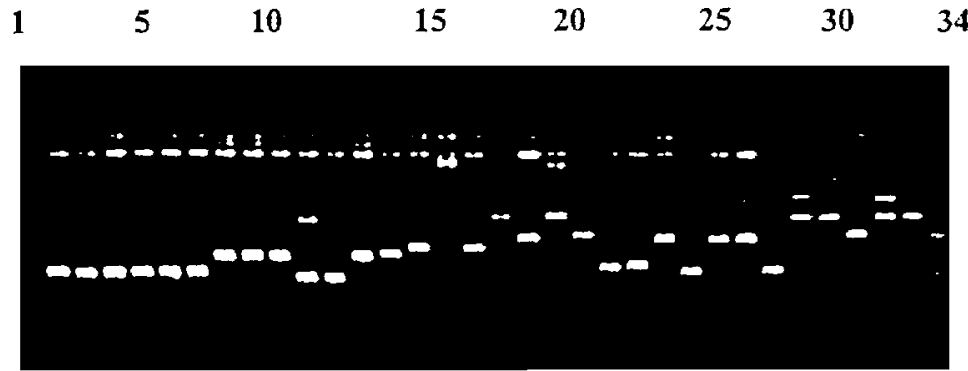

Fig. 5. PCR-ribotypes of various yeast species. A fragment of small subunit rRNA gene and ITS1 region is amplified in PCR and subjected to digestion by $M S P 1$ endonuclease and separated by electrophoresis. Lanes 1 and 34: molecular size markers; 2: Candida boidinii; 3: Pichia finlandica; 4: P. canadensis; 5: P. pini; 6: P. angusta; 7: Kluyveromyces delphensis; 8: Debaryomyces occidentalis; 9: D. robertsiae; 10: Saccharomycodes ludwigii; 11: Wickerhamia fluorescens; 12: Schizoblastosporium starkey-henrici; 13: Candida tenuis; 14: C. norvegica; 15: P. kluyveri; 16: D. polymorphus; 17: P. membranifaciens; 18: Zygosaccharomyces fermentati; 19: Saitoella comolicata; 20: Saccharomyces kluyveri; 21: S. dairensis; 22: S. cerevisiae; 23 and 24: S. paradoxus; 25 and 26: S. bayanus; 27: S. pastorianus; 28-30: Torulaspora delbrueckii; 31 and 32: T. globosa; 33: T. pretoriensis. All strains are from the collection of NCAIM. Courtesy of D. Dlauchy

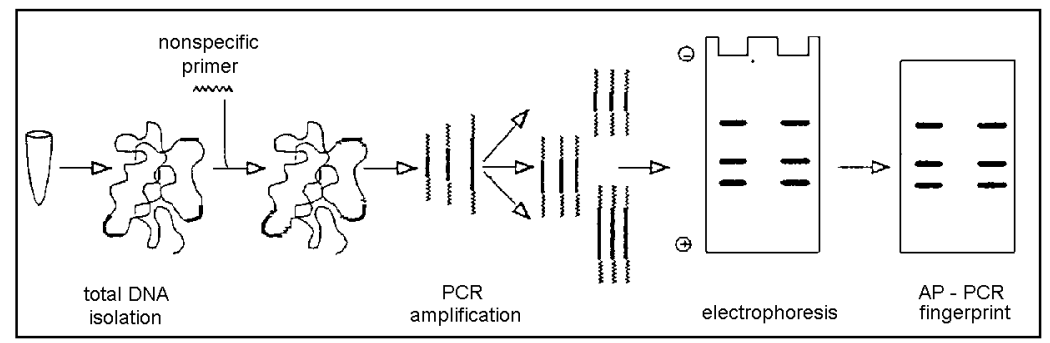

Fig. 6. Schematic diagram of random amplified polymorphic DNA (RAPD) analysis

A simple PCR method called random amplified polymorphic DNA (RAPD) allows discrimination both at species and subspecies level making use of synthetic 
oligonucleotide primers (MOLNÁR et al., 1995). In this variation of PCR, patterns are generated by the amplification of random DNA regions with a single, short primer of arbitrary nucleotide sequence (Fig. 6). In order to obtain amplified products, less stringent PCR conditions (low annealing temperatures) are applied, consequently, however, the method is less reproducible.

RAPD analysis and PCR-ribotyping permitted to study the dynamic changes in the yeast population and the succession of different yeast species during wine fermentation. These studies revealed also that the inoculated starter strain, although becoming predominant, does not suppress completely the members of the natural yeast microbiota (QUEROL et al., 1992). The mixed population contributes to the development of the complex bouquet of the wine. Investigations in Germany showed that a single starter strain used over the years established itself in the winery and appeared in the fermentation of different grape cultivars (SCHÜTZ \& GAFNER, 1993).

Such a detailed and specific information about the composition and changes of yeast population in the course of wine fermentation could only be obtained by the use of highly sensitive and effective molecular techniques. These will also offer reliable tools to monitor and control the possible application of genetically improved wine yeast strains.

The rapid development of molecular techniques opens new horizons in the microbiology and technology of wine making.

\section{References}

DEÁK, T. (1995): Methods for the rapid detection and identification of yeasts in foods. Trends Fd. Sci. Technol., 6, 287-292.

Dlauchy, D., ToRnai-LehoczKi, J. \& PÉTER, G. (1999): Restriction enzyme analysis of PCR amplified rRNA as a taxonomic tool in yeast identification. Syst. appl. Microbiol., 27, 445-453.

Guillamón, J.M., BARRIO, E. \& Querol, A. (1996): Characterization of wine yeast strains of the Saccharomyces genus on the basis of molecular markers: relationships between genetic distance and geographic or ecological origin. Syst. appl. Microbiol., 19, 122-132.

MARÁZ, A.\& DEÁK, T. (1990): Production and analysis of improved enological yeasts. Biotech. Forum Europe, 7, 63-68.

MARTINI, A. (1993): Origin and domestication of the wine yeast Saccharomyces cerevisiae. J. Wine Res., 4, $165-176$.

Molnár, O., Messner, R., Prillinger, H., Stahl, U. \& Slaviková, E. (1995): Genotypic identification of Saccharomyces species using random amplified polymorphic DNA analysis. Syst. appl. Microbiol., 18, $136-145$.

MoŽINA, S.S., DlaUCY, D., DEÁK, T. \& RASPOR, P. (1997): Identification of Saccharomyces sensu stricto and Torulaspora yeast by PCR ribotyping. Lett. appl. Microbiol., 24, 311-315.

MoŽINA, S.S. \& RASPOR, P. (1997): Molecular techniques of yeast identification in food processing. $F d$. Technol. Biotechnol., 35, 55-61.

Querol, A., BARrio, E., Huerta, T. \& RAMÓN, D. (1992): Molecular monitoring of wine fermentations conducted by active dry yeast strains. Appl. environ. Microbiol., 58, 2948-2953.

Querol, A., BARrio, E., \& RAMÓN, D. (1994): Population dynamics of natural Saccharomyces strains during wine fermentation. Int. J. Fd. Microbiol., 21, 315-323.

Querol, A. \& RAMÓN, D. (1996): The application of molecular techniques in wine microbiology. Trends Fd. Sci. Technol., 7, 73-78. 
SADDEKNI, G., MARÁZ, A. \& DEÁK, T. (1988): Breeding of wine yeasts having different physiological properties. -in: Holló, J., TÖRleY, D. (Eds.) Biotechnology and food industry. Akadémiai Kiadó, Budapest, pp. 123-134.

SchÜTZ, M. \& GAFNER, J. (1993): Analysis of yeast diversity during spontaneous and induced alcoholic fermentation determined by CHEF gel electrophoresis. J. appl. Bacteriol., 19, 551-558.

TORNAI-LEHOCZKI, J. \& Dlauchy, D. (1996): An opportunity to distinguish species of Saccharomyces sensu stricto by electrophoretic separation of the larger chromosomes. Lett. appl. Microbiol., 23, 227-230.

TÖRÖK, T., Mortimer, R.K., Romano, O., SuzZI, G. \& Polonelli, M. (1996): Quest for wine yeast - an old story revisited. J. ind. Microbiol., 17, 303-313.

Vezinhet, F., Hallet, J.N., Valade, M. \& Poulard, A. (1992): Ecological survey of wine yeast strains by molecular methods of identification. Am. J. Enol. Vitic., 43, 83-86. 